\title{
Microwave Power Transmission - A Next Generation Power Transmission System
}

\author{
${ }^{1}$ M.Venkateswara Reddy, ${ }^{2}$ K.Sai Hemanth, ${ }^{3} \mathrm{CH}$.Venkat Mohan \\ M.E,(Ph.D $)^{l}$ Department of EEE, ${ }^{2}$ B.Tech(EEE) student of, ${ }^{3}$ B.Tech(EEE) student of Vikas College of Engg \\ and Tech,India.
}

\begin{abstract}
In this paper, we present the concept of transmitting power without using wires i.e., transmitting power as microwaves from one place to another is in order to reduce the cost, transmission and distribution losses. This concept is known as Microwave Power transmission (MPT). We also discussed the technological developments in Wireless Power Transmission (WPT) which are required for the improment .The components which are requiredfor the development of Microwave Power transmission(MPT)are also mentioned along with the performance when they are connected to various devices at different frequency levels. The advantages, disadvantages, biological impacts and applications of WPT are also presented.
\end{abstract}

Keywords:Microwave Power transmission (MPT), Nikola Tesla,Rectenna,Solar Power Satellites (SPS), Wireless Power transmission (WPT).

\section{Introduction}

One of the major issue in power system is the losses occurs during the transmission and distribution of electrical power. As the demand increases day by day, the power generation increases and the power loss is also increased. The major amount of power loss occurs during transmission and distribution. The percentage of loss of power during transmission and distribution is approximated as $26 \%$. The main reason for power loss during transmission anddistribution is the resistance of wires used for grid. The efficiency of power transmission can be improved to certain level by using high strength composite over head conductors and underground cables that use high temperature super conductor. But, the transmission is still inefficient. According to the World Resources Institute (WRI), India's electricity grid has the highest transmission and distribution losses in the world - a whopping $27 \%$. Numbers published by various Indian government agencies put that number at $30 \%$, $40 \%$ and greater than $40 \%$. This is attributed to technical losses (grid's inefficiencies) and theft [1].

Any problem can be solved by state-of-the-art technology. The above discussed problem can be solved by choose an alternative option for power transmission which could provide much higher efficiency, low transmission cost and avoid power theft.Microwave Power Transmission is one of the promising technologies and may be the righteous alternative for efficient power transmission.

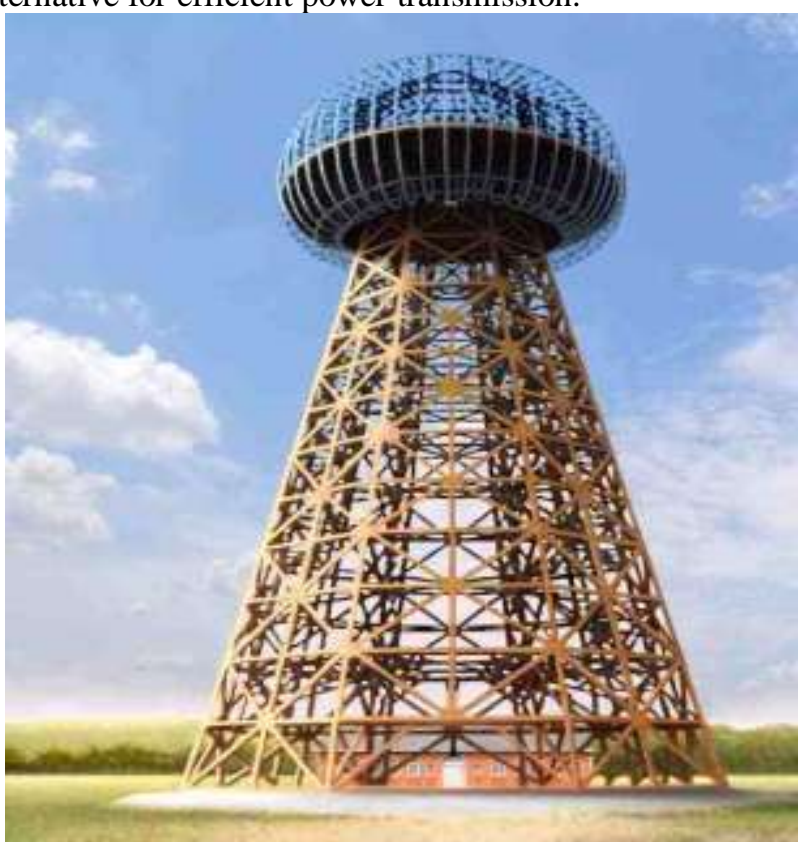

Figure1.The 187-foot wardenclyffe tower 


\section{Wireless Power Transmission}

Nikola Tesla he is who invented radio and shown us he is indeed the "Father of Wireless". Nikola Tesla is the one who first conceived the idea Wireless Power Transmission and demonstrated "the transmission of electrical energy without wires" that depends upon electrical conductivity as early as 1891[2]. In 1893, Tesla demonstrated the illumination of vacuum bulbs without using wires for power transmission at the World Columbian Exposition in Chicago. The Wardenclyffe tower shown in Figure 1 was designed and constructed by Tesla mainly for wireless transmission of electrical power rather than telegraphy [3].

In 1904, an airship ship motor of 0.1 horsepower is driven by transmitting power through space from a distance of least 100 feet [4]. In 1961, Brown published the first paper proposing microwave energy for power transmission, and in 1964 he demonstrated a microwave-powered model helicopter that received all the power needed for flight from a microwave beam at $2.45 \mathrm{GHz}$ [5] from the range of $2.4 \mathrm{GHz}-2.5 \mathrm{GHz}$ frequency band which is reserved 101 for Industrial, Scientific, and Medical (ISM) applications. Experiments in power transmission without wires in the range of tens of kilowatts have been performed at Goldstone in California in 1975 [6] and at Grand Bassin on Reunion Island in 1997 [7]. The world's first MPT experiment in the ionosphere called the MINIX (Microwave Ionosphere Non-linear Interaction Experiment) rocket experiment is demonstrated in 1983 at Japan [8]. Similarly, the world's first fuel free airplane powered by microwave energy from ground was reported in 1987 at Canada. This system is called SHARP (Stationary High - Altitude Relay Platform) [9]. In 2003, Dryden Flight Research Centre of NASA demonstrated a laser powered model airplane indoors. Japan proposed wireless charging of electric motor vehicles by Microwave Power Transmission in 2004. Powercast, a new company introduced wireless power transfer technology using RF energy at the 2007 Consumer Electronics Show [10]. A physics research group, led byProf. Marin Soljacic, at the Massachusetts Institute of technology (MIT) demonstrated wireless powering of a 60W light bulb with $40 \%$ efficiency at a $2 \mathrm{~m}$ (7ft) distance using two 60cm-diameter coils in 2007 [11]. Recently in 2008, Intel reproduced the MIT group's experiment by wirelessly powering a light bulb with $75 \%$ efficiency at a shorter distance [12].

2.2 Wireless Power Transmission System William C. Brown, the pioneer in wireless power transmission technology, has designed, developed a unit and demonstrated to show how power can be transferred through free space by microwaves. The concept of Wireless Power Transmission System is explained with functional block diagram shown in fig 2 . In the transmission side, the microwave power source generates microwave power and the output power is controlled by electronic control circuits. The wave guide ferrite circulator which protects the microwave source from reflected power is connected with the microwave power source through the Coax - Waveguide Adaptor.The tuner matches the impedance between the transmitting antenna and the microwave source. The attenuated signals will be then separated based on the direction of signal propagation by Directional Coupler. The transmitting antenna radiates the power uniformly through free space to the rectenna. In the receiving side, a rectenna receives the transmitted power and converts the microwave power into DC power. The impedance matching circuit and filter is provided to setting the output impedance of a signal source equal to the rectifying circuit. The rectifying circuit consists of Schottky barrier diodes converts the received microwave power into DC power

\subsection{Components of WPT System}

The Primary components of Wireless Power Transmission are Microwave Generator, Transmitting antenna and Receiving antenna (Rectenna). The components are described in this chapter.

\subsubsection{Microwave Generator}

The microwave transmitting devices are classified as Microwave Vacuum Tubes (magnetron, klystron, Travelling Wave Tube (TWT), and Microwave Power Module (MPM)) and Semiconductor Microwave transmitters (GaAs MESFET, GaN pHEMT, SiC MESFET, AlGaN/GaN HFET, and InGaAS). Magnetron is widely used for experimentation of WPT. The microwave transmission often uses $2.45 \mathrm{GHz}$ or $5.8 \mathrm{GHz}$ of ISM band. The other choices of frequencies are $8.5 \mathrm{GHz}$ [13], $10 \mathrm{GHz}[14]$ and $35 \mathrm{GHz}$ [15]. The highest efficiency over $90 \%$ is achieved at $2.45 \mathrm{GHz}$ among all the frequencies [15].

\subsubsection{Transmitting antenna}

The slotted wave guide antenna, microstrip patch antenna, and parabolic dish antenna are the most popular type of transmitting antenna. The slotted waveguide antenna is ideal for power transmission because of its high aperture efficiency (> 95\%) and high power handling capability.

\subsubsection{Rectenna}

The concept, the name 'rectenna' and the rectenna was conceived by W.C. Brown of Raytheon Company in the early of 1960s [16]. The rectenna is a passive element consists of antenna, rectifying circuit with a low 
pass filter between the antenna and rectifying diode. The antenna used in rectenna may be dipole, Yagi Uda,microstrip or parabolic dish antenna. The patch dipole antenna achieved the highest efficiency among the all. The performance of various printed rectenna is shown in Table I. Schottky barrier diodes (GaAs-W, Si, and GaAs) are usually used in the rectifying circuit due to the faster reverse recovery time and much lower forward voltage drop and good RF characteristics. The rectenna efficiency for various diodes at different frequency is shown in Table II.

\subsection{Types of WPT}

\subsubsection{Near-field techniques}

- Inductive Coupling

- Resonant Inductive Coupling (RIC)

- Air Ionization

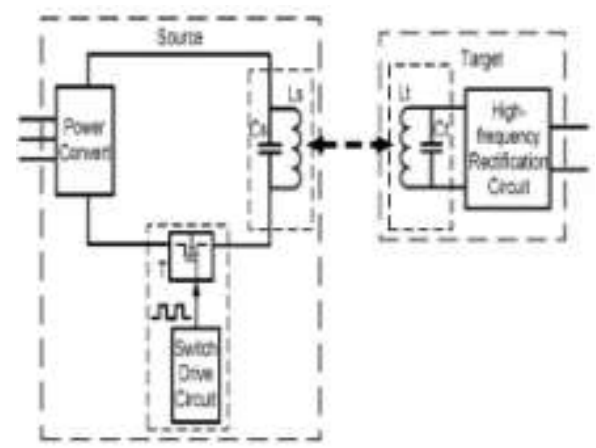

Figure2. Block diagram of RIC

\subsubsection{Far-field techniques}

- Microwave Power Transmission (MPT)

- LASER power transmission

\section{Advantages, Disadvantages, And Biological Impacts Of Wpt}

3.1 Advantages Wireless Power Transmission system would completely eliminates the existing high-tension power transmission line cables, towers and sub stations between the generating station and consumers and facilitates the interconnection of electrical generation plants on a global scale. It has more freedom of choice of both receiver and transmitters. Even mobile transmitters and receivers can be chosen for the WPT system. The cost of transmission and distribution become less and the cost of electrical energy for the consumer alsowould be reduced. The power could be transmitted to the places where the wired transmission is not possible. Loss of transmission is negligible level in the Wireless Power Transmission; therefore,the efficiency of this method is very much higher than the wired transmission. Power is available at the rectenna as long as the WPT is operating. The power failure due to short circuit and fault on cables would never exist in the transmission and power theft would be not possible at all.

\subsection{Disadvantages}

The Capital Cost for practical implementation of WPT seems to be very high and the other disadvantage of the concept is interference of microwave with present communication systems. Health hazards may occur.

\subsection{Biological Impacts}

Common beliefs fear the effect of microwave radiation. But the studies in this domain repeatedly proves that the microwave radiation level would be never higher than the dose received while opening the microwave oven door, meaning it is slightly higher. 
Table1. Performance of Printed Rectenna

\begin{tabular}{|l|l|l|}
\hline $\begin{array}{l}\text { Type of } \\
\text { Rectenna }\end{array}$ & $\begin{array}{l}\text { Operating } \\
\text { Frequency } \\
(\mathrm{GHz})\end{array}$ & $\begin{array}{l}\text { Measured } \\
\text { Peak } \\
\text { Conversion } \\
\text { Efficiency } \\
(\%)\end{array}$ \\
\hline Printed diplomo[9] & 2.45 & 85 \\
\hline Circular Patch[19] & 2.45 & 81 \\
\hline $\begin{array}{l}\text { Printed dual } \\
\text { rhombic [22] }\end{array}$ & 5.6 & 78 \\
\hline Square patch [15] & 8.51 & 66 \\
\hline
\end{tabular}

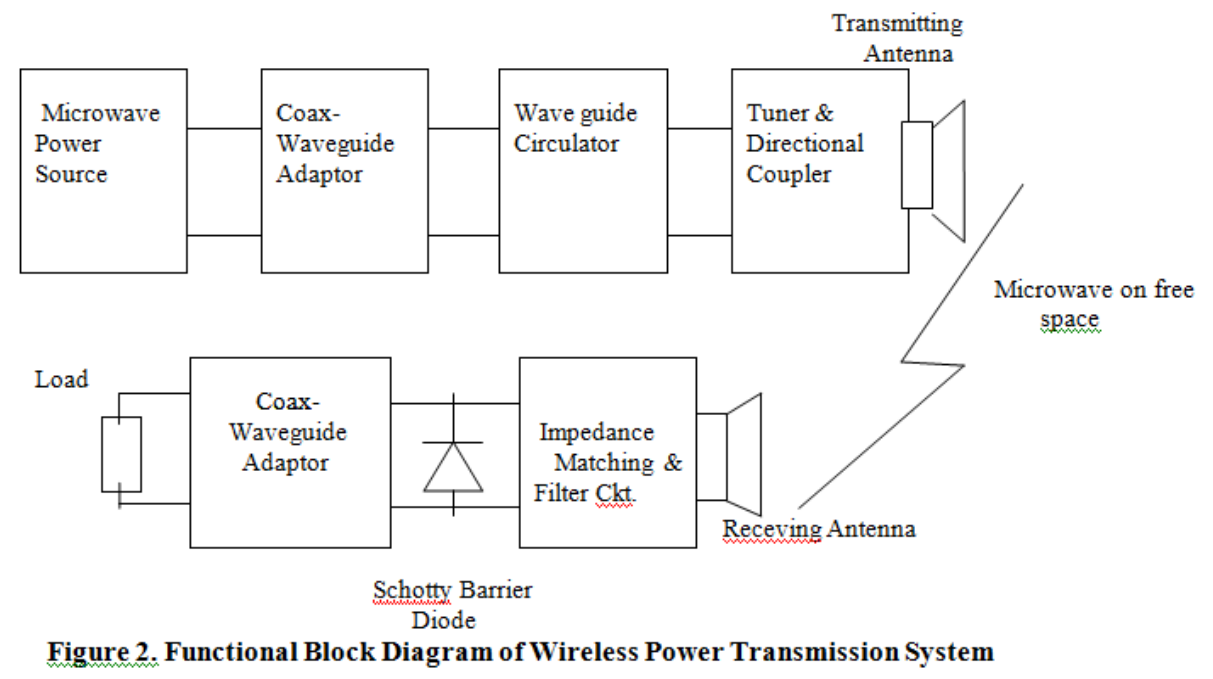

Table 2. Rectenna Efficiency for Various Diodes at Different Frequency

\begin{tabular}{|l|c|c|c|}
\hline $\begin{array}{l}\text { Frequency } \\
(\mathrm{GHz})\end{array}$ & $\begin{array}{c}\text { Schottky } \\
\text { Diode }\end{array}$ & $\begin{array}{c}\text { Measured } \\
\text { Efficiency } \\
(\%)\end{array}$ & $\begin{array}{c}\text { Calculated } \\
\text { Efficiency } \\
(\%)\end{array}$ \\
\hline $2.45[13]$ & GaAs-W & 92.5 & 90.5 \\
\hline $5.8[19]$ & $\mathrm{Si}$ & 82 & 78.3 \\
\hline $8.51[20]$ & $\mathrm{GaAs}$ & 62.5 & 66.2 \\
\hline
\end{tabular}

\section{Applications Of Wpt}

Generating power by placing satellites with giant solar arrays in Geosynchronous Earth Orbit and transmitting the power as microwaves to the earth known as Solar Power Satellites (SPS) is the largest application of WPT. Another application of WPT is moving targets such as fuel free airplanes, fuel free electric vehicles, moving robots and fuel free rockets. The other applications of WPT are Ubiquitous PowerSource (or) WirelessPower

Source, Wireless sensors and RF Power Adaptive Rectifying Circuits (PARC).

\subsection{Near-field energy transfer:}

1. Electric and Consumer electronics

2. Industrial purposes

\subsection{In Far-field energy transfer:}

1. Solar Power Satellites 
2. Energy to remote areas

3. Can broadcast energy globally (in future)

\section{Conclusion}

The concept of Microwave Power transmission (MPT) and Wireless Power Transmission system is presented. Thetechnological developments in Wireless Power Transmission(WPT), the advantages, disadvantages, biological impacts and applications of WPT are also discussed.This concept offers greater possibilities for transmitting power with negligible losses and ease of transmission than any invention or discovery heretofore made. Dr. Neville of NASA states "You don't need cables, pipes, or copper wires to receive power. We can send it to you like a cell phone call - where you want it, when you want it, in real time". We can expect with certitude that in next few years' wonders will be wrought by its applications if all the conditions are favourable.

\section{References}

[1] http://cleantechindia.wordpress.com/2008/07/16/indiaselectricity- transmission-and-distribution-losses/

[2] Nikola Tesla, My Inventions, Ben Johnston, Ed., Austin, Hart Brothers, p. 91,1982.

[3] Nikola Tesla, "The Transmission of Electrical Energy Without Wires as a Means for Furthering Peace," Electrical World and Engineer. Jan. 7, p. 21, 1905.

[4] The Electrician (London), 1904).

[5] W.C. Brown, J.R. Mims and N.I. Heenan, “An Experimental Microwave-Powered Helicopter”, 965 IEEE International Convention Record, Vol. 13, Part 5, pp.225-235.

[6] Brown., W. C. (September 1984). "The History of Power Transmission by Radio Waves". Microwave Theory and Techniques, IEEE Transactions on (Volume: 32, Issue: 9 On page(s): $1230-\quad 1242$ + ISSN: 0018-9480). http://ieeexplore.ieee.org/xpl/freeabs all.jsp?arnumber=1132833.

[7] POINT-TO-POINT WIRELESS POWER TRANSPORTATION IN REUNION ISLAND 48th International Astronautical Congress, Turin, Italy, 6-10 October 1997 - IAF-97- R.4.08 J. D. Lan Sun Luk, A. Celeste, P. Romanacce, L. Chane Kuang Sang, J. C. Gatina - University of La Réunion - Faculty of Science and Technology.

[8] Matsumoto, H.N. Kaya, I. Kimura, S. Miyatake, M. Nagatomo, and T. Obayashi, MINIX Project toward the Solar Power Satellites -- Rocket experiment of microwave energy transmission and associated plasma physics in the ionosphere, ISAS space energy symposium, pp 69-76, 1986.

[9] J.J. Schelesak, A. Alden and T. Ohno, A microwave powered high altitude platform, IEEE MTT-S Int. Symp. Digest, pp - 283- 286, 1988 .

[10] "CES Best of 2007"

[11] "Goodbye wires...MIT News. 2007-06-07. http://web.mit.edu/newsoffice/2007/wireless-0607.html.

[12] www.tgdaily.com

[13] L.W. Epp, A.R. Khan, H.K. Smith, and R.P. Smith, “A compact dual-polarized $8.51 \mathrm{GHz}$ rectenna for high-voltage (50 V) actuator applications," IEEE Trans. Microwave Theory Tech., vol. 48, pp. 111-120, 2000.

[14] T-WYoo and K. Chang, "Theoretical and experimental development of 10 and 35 GHz rectennas," IEEE Trans. Microwave Theory Tech., vol. 40, pp. 1259-1266, 1992.

[15] P. Koert and J.T. Cha, "35 GHz rectenna development," in Proc. 1st Annu. Wireless Power Transmission Conf., San Antonio,TX, 1993, pp. 457-466.

[16] Brown, W.C, "The History of the Development of the Rectenna" Proc. Of SPS microwave systems workshop, pp.271 - 280, Jan 1980 .

[17] www.howstuffworks.com (How Micro Ovens Work - A Cooking Oven for the 21st century. By Gabriel Gache)

[18] J.C. Lin, "Biological aspects of mobile communication fields," Wireless Networks, vol. 3, pp. 439-453, 1997.

[19] M. Onda,M. Fujita, Y. Fujino, N. Kaya, K. Tomita, andMYamada, "A stratospheric stationary LT Aplatform concept and ground-tovehiclemicrowave power transmission tests," in 37th AIAA Aerospace Sciences Meeting and Exhibit, Reno, NV, 1999 , pp. 1-7.

[20] P. Koert and J.T. Cha, "35 GHz rectenna development," in Proc.1st Annu. Wireless Power Transmission Conf., San Antonio, TX, 1993, pp. 457-466.

[21] T.-W. Yoo, "Experimental and theoretical study on $35 \mathrm{GHz}$ RF-to-DC power conversion receiver for millimeter-wave beamed power transmission,” Ph.D. dissertation, Dept. of Electrical Engineering, Texas A\&M Univ., Dec. 1993. 